\title{
Description of a new phlebotomine species, Martinsmyia reginae sp. nov. (Diptera: Psychodidae: Phlebotominae) from a cave in the state of Tocantins Brazil
}

\author{
Gustavo Mayr de Lima Carvalho ${ }^{1 /+}$, Reginaldo Peçanha Brazil ${ }^{2}$, \\ Cristiani de Castilho Sanguinette ${ }^{1}$, José Dilermando Andrade Filho'
}

'Coleção de Flebotomíneos, Centro de Referência Nacional e Internacional para Flebotomíneos, Instituto René Rachou-Fiocruz, Av. Augusto de Lima 1715, 30190-002 Belo Horizonte, MG, Brasil 'Instituto Oswaldo Cruz-Fiocruz, Rio de Janeiro, RJ, Brasil

As inhabitants of forested areas, caves and anthropic environments, the phlebotomines deserve special attention because some species are able to transmit trypanosomatids, bacteria and viruses to vertebrates. Phlebotomines are also a nuisance because they cause painful bites, which may ultimately produce allergic manifestations. The lack of information about the presence and behaviours of sand flies in caves has aroused the curiosity of researchers for a long time. In the present paper, we describe a new species of sand fly that was captured in a cave located in the municipal district of Arraias in the southeastern region of the state of Tocantins. The morphological features of this new species permit it to be included in the alphabetica group of the Martinsmyia genus.

Key words: Martinsmyia reginae sp. nov. - sand fly - cave - Tocantins

Phlebotomines are invertebrate hosts of Leishmania species, which cause leishmaniases and are responsible for the transmission of Leishmania to humans and other mammals. They are also the vectors of arboviruses and the causative agents of bartonellosis and their bites cause allergic reactions (Young \& Duncan 1994). Caves are ecotopes that are significantly different from their external surrounding environments and sand flies are constantly found among the insects that live in caves or visit their surrounding areas (Andrade Filho et al. 2001, Galati et al. 2006). Several caves are opened to tourists before any scientific studies are conducted and as a result, valuable geological and biological information about the caves is lost.

The present paper describes a new species of sand fly that was captured in 1965 in a cave located in the municipal district of Arraias in the southeastern region of the state of Tocantins (TO) at a distance of $413 \mathrm{~km}$ from Palmas, the capital of the state. The cave, which was previously known as Lapa das Cabeceiras and is now called Grutas da Lapa, consists of four large rooms that are about $40 \mathrm{~m}$ long and $20 \mathrm{~m}$ high.

\section{MATERIALS AND METHODS}

Sand flies were mounted in Canada balsam, measured with a binocular Olympus CH-2 microscope that was fitted with a micrometer objective and drawn with the help of a camera lucida. The measurements are given

\footnotetext{
Financial support: Fiocruz, Capes, Faperj

+ Corresponding author: gumayr@cpqrr.fiocruz.br

Received 17 November 2009

Accepted 13 April 2010
}

in micrometers. The nomenclature and classification is identical to the nomenclature and classification that was previously proposed by Galati (2003) and the abbreviations are identical to the abbreviations of the names for the phlebotomine genera by Marcondes (2007). The description of the new species was based on six females and eight males, which were associated by their morphological characteristics and by their capture locations and times and includes all of the specimens from both sexes in the same genus and group.

\section{Martinsmyia reginae sp. nov.}

(Figs 1-9)

Male: sand fly of medium size, measurement $c a$. $2.868(2.680 \pm 128.4 ; \mathrm{n}=7)$ in length, general colour light brown. Head (Fig. 1) : four hundred and fourteen $(424 \pm$ $9.0 ; \mathrm{n}=7)$ long and $294(300 \pm 15.7 ; \mathrm{n}=7)$ wide. Head length/head width ratio 1.41:1 $(1.42 \pm 0.08 \mathrm{n}=7)$. Clypeus $143(148 \pm 8.3 ; \mathrm{n}=7)$ long; clypeus length/head length ratio $0.35: 1(0.35: 1 \pm 0.01 ; \mathrm{n}=7)$. Eye $143(156 \pm 13.2 ; \mathrm{n}=7)$ long and $91(96+12.2 ; \mathrm{n}=7)$ wide; eye length/head length ratio $0.35: 1(0.37: 1 \pm 0.03 ; \mathrm{n}=7)$. Interocular distance $124(123 \pm 9.4 ; \mathrm{n}=7)$. Labrum-epipharynx (LE) $271(294 \pm 11.5 ; \mathrm{n}=7)$. LE/head length ratio 0.65:1 $(0.69 \pm 0.03 ; \mathrm{n}=7)$. Antenna with simple and short ascoid. Antennomere lengths: AIII $316(329 \pm 12.3 ; \mathrm{n}=$ 7); AIV 147 (144 $\pm 5.9 ; \mathrm{n}=7)$; AV $147(144 \pm 5.9 ; \mathrm{n}=$ 7); AXV < AXVI (AXV < AXVI; $n=4)$. AIII, AIV, AXIV, AXV, AXVI with papilla; ratios: AIII/head length 0.76:1 (0.78:1 $\pm 0.03 ; \mathrm{n}=7)$; AIII/LE 1.17:1 (1.12:1 $\pm 0.04 ; \mathrm{n}=7$ ). Palpal formula 1.4.2.3.5 [1.4.2.3.5; $\mathrm{n}=$ 5 and 1.4.(2,3).5; $\mathrm{n}=2$ ]. Palpomere lengths: P1 36 (32 $\pm 3.4 ; \mathrm{n}=7) ; \mathrm{P} 2151(154 \pm 10.7 ; \mathrm{n}=7) ; \mathrm{P} 3157(158 \pm$ 8.0; $\mathrm{n}=7) ; \mathrm{P} 472$ (78 $\pm 4.3 ; \mathrm{n}=7)$; P5 $223(235 \pm 5.7 ; \mathrm{n}$ $=7$ ). The Newstead spines are implanted in the median region of the third palpomere Ventrocervical sensillae: absent. Thorax: Proepimeral setae present, $4-2[(5-5 ; n=$ 


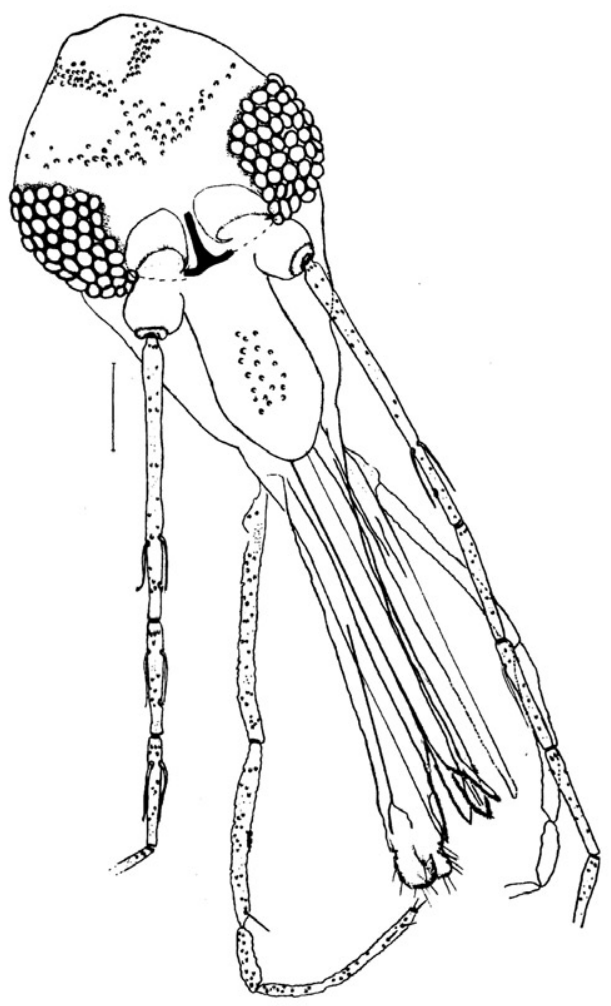

Fig. 1: Martinsmyia reginae sp. nov. (paratype male). Head, frontal view. $\mathrm{Bar}=100 \mu \mathrm{m}$.

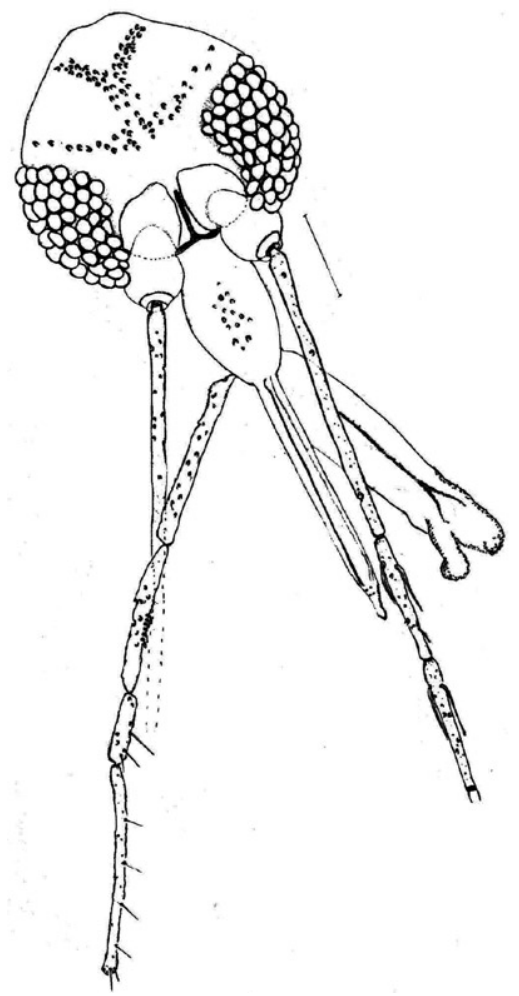

Fig. 2: Martinsmyia reginae sp. nov. (paratype female). Head, frontal view. $\mathrm{Bar}=100 \mu \mathrm{m}$.
2), (3-3; $\mathrm{n}=2),(4-3 ; \mathrm{n}=1),(7-6 ; \mathrm{n}=1),(6-4 ; \mathrm{n}=1)]$ and anepisternal superior setae present, $4-4[(8-9 ; n=2),(7-8$; $\mathrm{n}=2),(4-3 ; \mathrm{n}=1),(6-7 ; \mathrm{n}=1)]$; setae on the anterior region of the katepisternum absent. Wing (Fig. 3) measurement $2.224(2.214 \pm 76.9 ; \mathrm{n}=7)$ long and $542(556 \pm 8.7$; $\mathrm{n}=7$ ) wide at the maximum width. Length/width ratio 4.1:1 (3.98:1 $\pm 0.1 ; \mathrm{n}=7)$. Length of the vein sections: $\mathrm{R}_{5}$ $1,231(1.240 \pm 50.7 ; \mathrm{n}=7)$; alpha $508(498 \pm 23.7 ; \mathrm{n}=7)$; beta 327 (324 $\pm 39.9 ; \mathrm{n}=7)$; gamma $135(158 \pm 14.5 ; \mathrm{n}=$ 7); delta $158(168 \pm 37.2 ; \mathrm{n}=7)$. Legs: anterior, median and posterior, respectively: femur $869(877 \pm 22.0 ; \mathrm{n}=6)$, $745(777 \pm 19.5 ; \mathrm{n}=6)$ and $813(838 \pm 14.8 ; \mathrm{n}=5)$; tibia $1.411(1.460 \pm 38.3 ; \mathrm{n}=6), 1.524(1.598 \pm 53.0 ; \mathrm{n}=6)$ and $1.694(1.725 \pm 76.5 ; \mathrm{n}=5)$; tarsomere I $1,016(1.037 \pm$ 25.3; $\mathrm{n}=6), 1.039(1.056 \pm 32.6 ; \mathrm{n}=6)$ and $1.084(1.118 \pm$ $61.4 ; \mathrm{n}=5)$; tarsomeres II + III + IV + V $707(768 \pm 7.0$; $\mathrm{n}=6), 756(811 \pm 4.5 ; \mathrm{n}=6)$ and $790(845 \pm 9.2 ; \mathrm{n}=5)$. Terminalia (Fig. 5): gonostyle $135(143 \pm 4.9 ; \mathrm{n}=7)$ long with four spines: one apical, one upper external that is implanted near the apical, one lower external and one internal spine that is implanted more basal than the lower external. Subterminal seta absent. Gonocoxite 215 (219 $\pm 5.8 ; \mathrm{n}=7)$ long and $66(67 \pm 3.0 ; \mathrm{n}=7)$ wide without setae. Paramere straight with dorsal setae inserted in the basal third of the structure and ventral setae inserted in the basal region. Lateral lobe $248(239 \pm 6.1 ; \mathrm{n}=7)$ long and $28(30 \pm 3.9 ; \mathrm{n}=7)$ wide. Lateral lobe/gonocoxite ratio 1.15:1 $(1.09 \pm 0.04 ; n=7)$. Conical aedeagus. Genital filament (Fig. 6) $339(353 \pm 21.2 ; n=7)$ long and 2.8
$(2.8 ; \mathrm{n}=7)$ wide and genital pump $135(138 \pm 8.2 ; \mathrm{n}=7)$. Genital filament/genital pump ratio 2.51:1 (2.55 \pm 0.16 ; $\mathrm{n}$ $=7$ ). Type of genital filaments slender and beak-shaped.

Female: sand fly of medium size, measuring ca. $2.800(2.981 \pm 110.3 ; \mathrm{n}=5)$ in length. Colouration is similar to the male. Head (Fig. 2): four hundred eightysix $(514 \pm 16.9 ; \mathrm{n}=5)$ long and $327(359 \pm 9.6 ; \mathrm{n}=5)$ wide. Head length/head width ratio 1.49:1 $(1.43 \pm 0.04$; $\mathrm{n}=5)$. Clypeus $203(211 \pm 12.7 ; \mathrm{n}=5)$ long; clypeus length/head length ratio 0.42:1 $(0.41: 1 \pm 0.01 ; n=5)$. Eye $169(190 \pm 5.2 ; \mathrm{n}=5)$ long and $99(107+6.3 ; \mathrm{n}=5)$ wide; eye length/head length $0.35: 1(0.37: 1 \pm 0.01 ; n=5)$. Interocular distance $143(146+3.6 ; \mathrm{n}=5)$. LE $406(431$ $\pm 14.7 ; \mathrm{n}=5)$. LE/head length 0.84:1 $(0.84 \pm 0.03 ; \mathrm{n}=$ $5)$. Antenna with simple and short ascoid. Antennomere lengths: AIII 305 (316; $\mathrm{n}=5)$; AIV $136(136 ; \mathrm{n}=5)$; AV $136(124 ; \mathrm{n}=5)$; AXV < AXVI (AXV < AXVI; $\mathrm{n}=3)$. AIII, AIV, AXIV, AXV and AXVI with papilla; ratios: AIII/head length 0.63:1 $(0.62: 1 \pm 0.02 ; \mathrm{n}=5)$; AIII/LE 0.75:1 $(0.73: 1 \pm 0.02 ; n=5)$. Palpal formula 1.4.3.2.5 $(\mathrm{n}=$ 3). Palpomere lengths: $\mathrm{P} 142(40 \pm 4.0 ; \mathrm{n}=3) ; \mathrm{P} 2161(159$ $\pm 12.0 ; \mathrm{n}=3) ; \mathrm{P} 3179(170 \pm 13.4 ; \mathrm{n}=3) ; \mathrm{P} 4$ lost in holotype $(117 \pm 10.4 ; \mathrm{n}=3)$; P5 lost in holotype ( $338 \pm 16.2$; $\mathrm{n}=3$ ). The Newstead spines are implanted in the median region of the third palpomere. Cibarium with four posterior (horizontal) teeth that are barely developed and individualised not fused in their base. The central teeth have more space between them when compared to the 


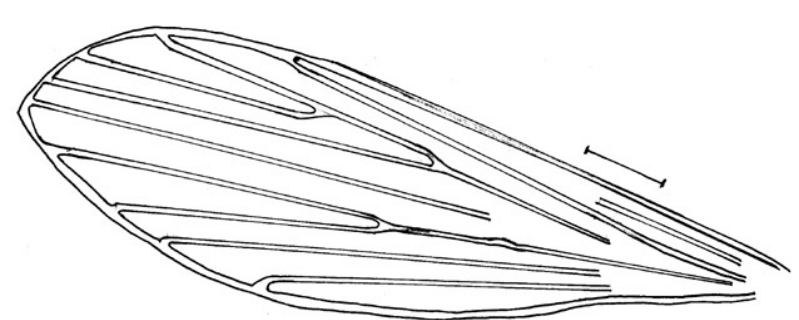

Fig. 3: Martinsmyia reginae sp. nov. (holotype male). Wing. Bar $=250 \mu \mathrm{m}$.

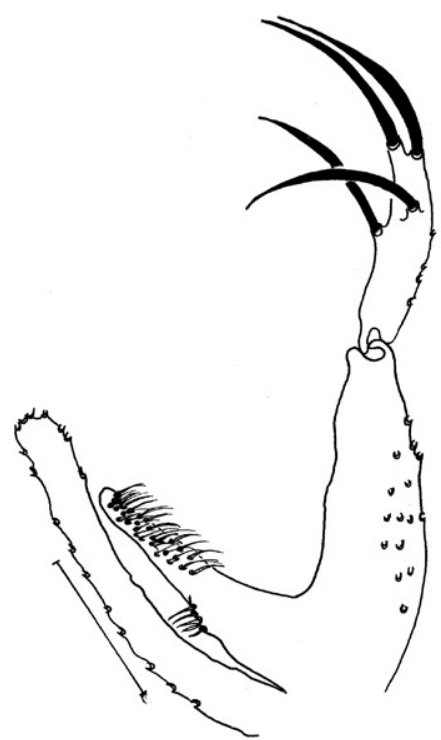

Fig. 5: Martinsmyia reginae sp. nov. (holotype male). Terminalia. Bar $=100 \mu \mathrm{m}$.

external ones. The anterior (vertical) teeth are present in large numbers and are situated below the posterior teeth (Fig. 7). The sclerotised area is well defined and the sclerotised arch is complete. Unarmed pharynx. Lacinia of the maxilla with nine external teeth in a single longitudinal row. Ventrocervical sensillae: absent. Thorax: proepimeral setae present, $3-3[(5-5 ; \mathrm{n}=1),(4-$ $4 ; \mathrm{n}=3),(3-3 ; \mathrm{n}=1)]$ and anepisternal superior setae present, $6-5[(4-3 ; \mathrm{n}=1),(3-3 ; \mathrm{n}=1),(8-6 ; \mathrm{n}=1),(5-5$; $\mathrm{n}=2)]$; setae on the anterior region of the katepisternum absent. Wing (Fig. 4) measurement 2.348 (2.281 \pm 36.7 ; $\mathrm{n}=5)$ long and $621(625 \pm 20.7 ; \mathrm{n}=5)$ wide at the maximum width. Length/width ratio 3.78:1 $(3.65: 1 \pm 0.14)$. Length of the vein sections: $\mathrm{R}_{5} 1.422(1.350 \pm 70.6 ; \mathrm{n}=5)$; alpha $508(576 \pm 41.6 ; \mathrm{n}=5)$; beta $350(343 \pm 30.4 ; \mathrm{n}=5)$; gamma $169(165 \pm 9.8 ; \mathrm{n}=5)$; delta $181(165 \pm 45.9 ; \mathrm{n}=5)$. Legs, anterior, median and posterior, respectively: femur $903(933 \pm 45.4 ; \mathrm{n}=3), 790(822 \pm 40.8 ; \mathrm{n}=4)$ and 858 $(903.3 \pm 49.1 ; \mathrm{n}=3)$; tibia $1.287(1.329 \pm 64.1 ; \mathrm{n}=3)$, $1.400(1.499 \pm 69.1 ; n=4)$ and $1.637(1.675 \pm 65.2 ; n=3)$; tarsomere I $960(971 \pm 51.4 ; n=3), 1.005(.1005 \pm 47.0 ; n$

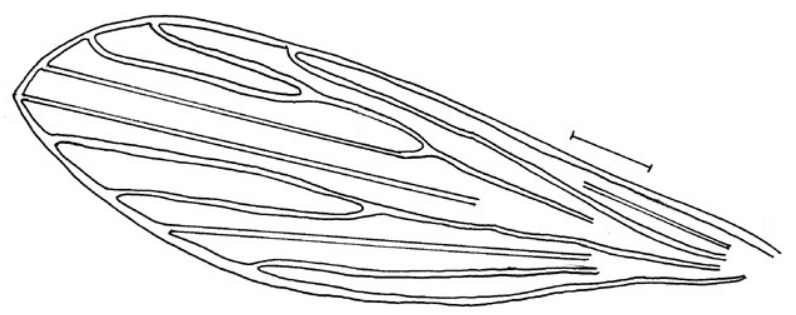

Fig. 4: Martinsmyia reginae sp. nov. (paratype female). Wing. Bar $=250 \mu \mathrm{m}$.

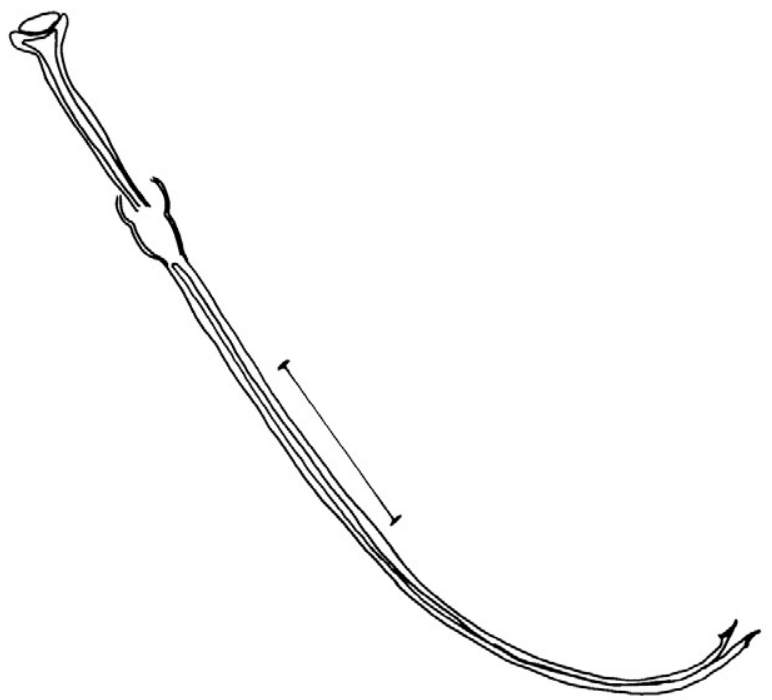

Fig. 6: Martinsmyia reginae sp. nov. (holotype male). Genital pump and filaments. $\operatorname{Bar}=100 \mu \mathrm{m}$.

$=4)$ and $1.084(1.107 \pm 40.8 ; \mathrm{n}=3)$; tarsomeres II + III + $\mathrm{IV}+\mathrm{V} 779(820 \pm 34.6 ; \mathrm{n}=3), 802(810 \pm 35.0 ; \mathrm{n}=4)$ and $847(850 \pm 45.6 ; n=3)$. Spermathecae (Figs 8, 9): $44(40$ $\pm 5.7 ; \mathrm{n}=2)$ long and $11(13 \pm 2.1 ; \mathrm{n}=2)$ wide at the maximum width. The body of the spermatheca consists of 6-7 rings that are approximately equal diameters. The head of the spermathecae displays some fine bristles inserted in the apex. The individual and common sperm ducts are smooth-walled, the latter being relatively short compared to the first. The individual duct is $138(151 ; \mathrm{n}=1)$ in length and the common duct is $28(22 ; \mathrm{n}=1)$ long. Cercus $105(108 \pm 7.0 ; n=5)$ long.

Type-data - Holotype male $(36,282)$ and allotype female $(36,286)$ were collected with manual aspirators in a limestone cave at the Grutas da Lapa location in the municipal district of Arraias, TO, Brazil on 25 Sep 1965 (Leôncio A Col.), together with seven male $(6,275-36,281)$ and five female paratypes $(36,283-36,285 ; 36,287$ and $36,288)$. The type-material is deposited in the Coleção de Flebotomíneos of the Instituto René Rachou-Fiocruz, Belo Horizonte, Brazil. 


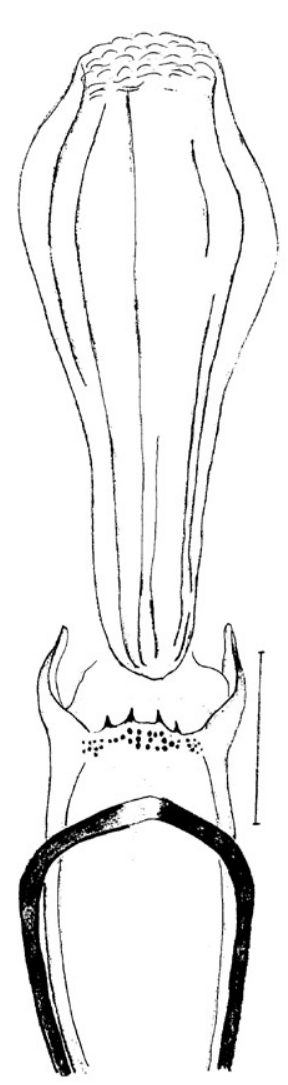

Fig 7: Martinsmyia reginae sp. nov. (paratype female). Pharynx and cibarium. Bar $=100 \mu \mathrm{m}$.

Etymology - The name Ma. reginae sp. nov. has been given to the new species in honour of Regina Maria de Oliveira Rezende, who dedicated more than 40 years of work to the Coleção de Flebotomíneos of the Instituto René Rachou/Fiocruz.

\section{DISCUSSION}

The morphological features of the new species, such as the absence of ventrocervical sensillae, fifth palpomeres that are greater than the third and a long clypeus, permit its inclusion in the alphabetica group of the Martinsmyia genus. Presently, eight species comprise this group (Galati 2003): Martinsmyia alphabetica (Fonseca, 1936), Martinsmyia brisolai (Le Pont \& Desjeux, 1987), Martinsmyia minasensis (Mangabeira, 1942), Martinsmyia mollinedoi (Le Pont \& Desjeux, 1991), Martinsmyia oliveirai (Martins, Silva \& Falcão, 1970), Martinsmyia pisuquia (Ogusuku, Guevara, Revilla, Inga \& Pérez, 2001), Martinsmyia quadrispinosa (Floch \& Chassignet, 1947) and Martinsmyia waltoni (Arias, Freitas \& Barrett, 1984).

The males and females have a proboscis longer than the proboscises found in other species of this group. $M a$. reginae sp. nov. males are distinguished from the other species by the length of the genital filaments, the disposition of the spines on the gonostyle and the shape of the paramere. Ma. alphabetica is the only species of the group with five, sometimes six, spines on the gonostyle.

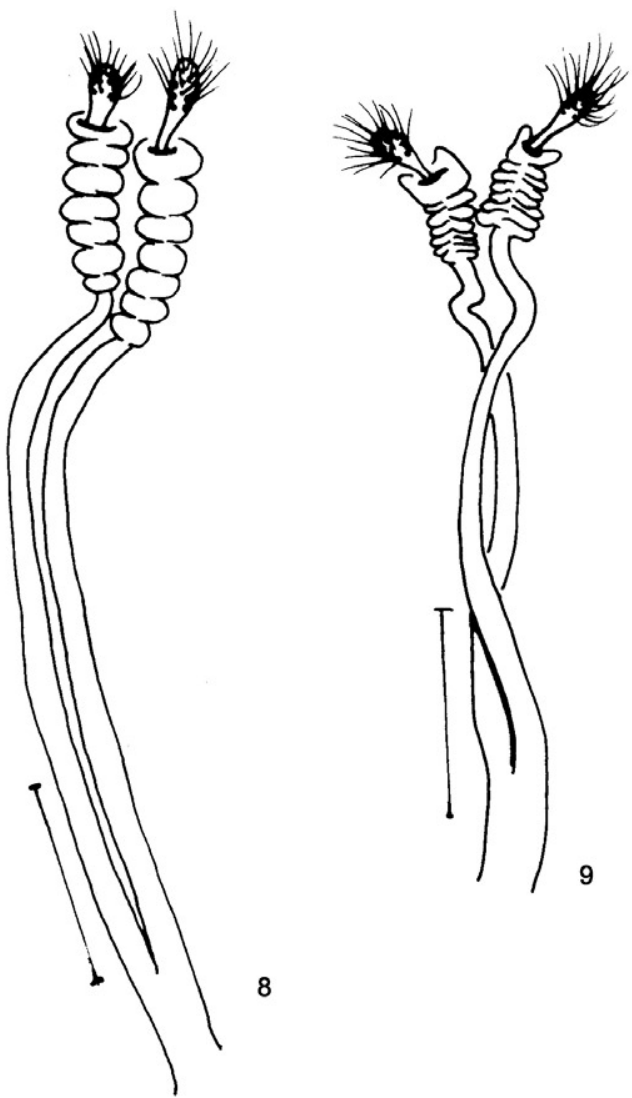

Figs 8, 9: Martinsmyia reginae sp. nov. (paratypes female). Spermathecae. Bar $=100 \mu \mathrm{m}$.

Ma. brisolai and Ma. waltoni are distinguished by their genital filament/genital pump ratios, which are equivalent to 2.0. In this new species, the genital filament/ genital pump ratio equals 2.5. The apex of the genital filament is also distinct in each of the three species.

The new species displays a straight paramere, while the apical part of the paramere is curved toward the gonocoxite in Ma. oliveirai and Ma. mollinedoi. The arrangement of the spines on the gonostyle in Ma. oliveirai and Ma. mollinedoi is also distinct from the arrangement that is present on the new species.

The lateral lobe of the new species is longer than the gonocoxite, which also occurs in Ma. quadrispinosa and distinguishes the new species from Ma. pisuquia and Ma. minasensis. The new species is differentiated from Ma. quadrispinosa by the shape of its paramere and the smaller terminalia (Floch \& Chassignet 1947).

The females of the new species are distinguished from the other species of the group by several factors, which include the length of the common duct of the spermathecae, the width of the individual ducts and elements of the cibarium. Because the cibarium of the new species contains four posterior (horizontal) underdeveloped and individualised teeth that are not fused at their bases, the new species is different from other species in the group. $M a$. waltoni has four pairs of posterior teeth, Ma. pisuquia has 
only one pair of posterior teeth and Ma. oliveirai presents four posterior teeth that are fused into two bases, which each contain two teeth. Ma. brisolai is distinguished from the new species by its somewhat rectangular sclerosed arch, which appears rounded in the new species.

The spermathecae of the new species are composed of six or more rings that gradually increase in diameter from the base to the apex. This characteristic of the spermathecae distinguishes the new species from $M a$. alphabetica, which contains spermathecae that consist of 4-5 rings that are smaller in diameter near the center rather than at the base or the apex. Ma. reginae sp. nov. displays individual ducts that are about six times longer than the common duct. The individual and common ducts are regularly fine and smooth, which are unlike the thicker and more wrinkled ducts of Ma. mollinedoi.

With the addition of this new species, the alphabeti$c a$ group within the genus of Martinsmyia now consists of nine species. Five of the species occur in Brazil (Ma. alphabetica, Ma. oliveirai, Ma. minasensis, Ma. waltoni and now Ma. reginae) and two of the species (Ma. oliveirai and Ma. reginae) are found in TO.

\section{REFERENCES}

Andrade Filho JD, Silva ACL, Falcão AL 2001. Phlebotomine sand flies in the state of Piauí, Brazil (Diptera: Psychodidae: Phlebotominae). Mem Inst Oswaldo Cruz 96: 1085-1087.

Floch H, Chassignet R 1947. Phlébotomes de Guyane Française (XX). $P$. dendrophyllus Mangabeira, 1942, et $P$. quadrispinosus $\mathrm{n}$. sp. Inst Pasteur Guyane 155: 5 pp.

Galati E 2003. Morfologia e taxonomia dos flebotomíneos. In EF Rangel, R Lainson (eds.), Flebotomíneos do Brasil, Fiocruz, Rio de Janeiro, p. 23-206.

Galati EAB, Nunes VLB, Boggiani PC, Dorval MEC, Cristaldo G, Rocha HC, Oshiro ET, Damasceno-Júnior GA 2006. Phlebotomines (Diptera: Psychodidae) in forested areas of the Serra da Bodoquena, state of Mato Grosso do Sul, Brazil. Mem Inst Oswaldo Cruz 101: 175-193.

Marcondes CB 2007. A proposal of generic and subgeneric abbreviations for phlebotomine sandflies (Diptera: Psychodidae: Phlebotominae) of the world. Entomol News 118: 351-356.

Young DG, Duncan MA 1994. Guide to the identification and geographic distribution of Lutzomyia sand flies in Mexico, the West Indies, Central and South America (Diptera: Psychodidae). Mem Amer Ent Inst 54: 1-881. 